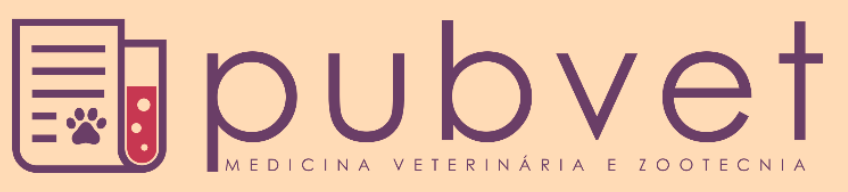

https://doi.org/10.31533/pubvet.v15n10a928.1-5

\title{
Fratura epifisária proximal de úmero em cão: Relato de caso
}

\author{
Rainer da Silva Reinstein ${ }^{1 *} \bullet \mathbb{D}$, Franciéli Mallmann Pozzobon ${ }^{2} \bullet \mathbb{D}$, João Eduardo Wallau \\ Schossler $^{3}{ }^{\circ}$, Daniel Curvello de Mendonça Müller ${ }^{30}$ \\ ${ }^{I}$ Aluno da Universidade Federal de Santa Maria, Programa de Pós-graduação em Medicina Veterinária. Santa Maria-RS Brasil. \\ ${ }^{2}$ Aluno da Universidade Federal de Santa Maria, Curso de Graduação em Medicina Veterinária, Santa Maria-RS Brasil. \\ ${ }^{3}$ Professor da Universidade Federal de Santa Maria, Departamento de Clínica de Pequenos Animais. Santa Maria-RS Brasil. \\ *Autor para correspondência, E-mail: rainerreinstein@gmail.com
}

Resumo. As fraturas de ossos longos têm papel de destaque na rotina clínico-cirúrgica da medicina veterinária visto a frequência em que ocorrem, sendo nítida a necessidade de intervenções ortopédicas reparadoras. As placas de crescimento são consideradas menos resistentes do que as estruturas que a circundam, como ossos e ligamentos, tornando a região mais suscetível a lesões. Em caso de fratura, a lesão deve ser bem avaliada, buscando o melhor método de reparo, com o menor prejuízo iatrogênico causado pelo cirurgião, mas com estabilização óssea satisfatória. Relata-se o caso de um canino jovem, sem raça definida, atendido no Hospital Veterinário Universitário da Universidade Federal de Santa Maria, apresentando fratura Salter-Harris tipo I na porção proximal de úmero direito, tratada com pinos intramedulares e banda de tensão. O método, ainda que simples, apresenta boa estabilidade do foco de fratura e retorno do apoio do membro sem comprometimento de tecidos moles.

Palavras chave: Cachorro, cirurgia, linha de crescimento, osteossíntese

\section{Proximal epiphyseal fracture of humerus in dog: Case report}

\begin{abstract}
Long bone fractures play an important role in the clinical-surgical routine of veterinary medicine, given the frequency in which they occur, and the need for reparative orthopedic interventions is clear. Growth plates are considered less resistant than the surrounding structures, such as bones and ligaments, making the region more susceptible to injury. In case of fracture, the injury must be well evaluated, looking for the best repair method, with the least iatrogenic damage caused by the surgeon, but with satisfactory bone stabilization. We report the case of a young canine, mixed breed, attended at the Veterinary University Hospital of the Federal University of Santa Maria, presenting a Salter-Harris type I fracture in the proximal portion of the right humerus, treated with intramedullary pins and tension band. The method, although simple, presents good stability of the fracture focus and return of limb support without soft tissue involvement.
\end{abstract}

Keywords: Dog, surgery, growth line, osteosynthesis

\section{Fractura epifisaria proximal del húmero en un perro: Reporte de caso}

Resumen. Las fracturas de huesos largos juegan un papel importante en la rutina clínicoquirúrgica de la medicina veterinaria, dada la frecuencia en la que ocurren, y es clara la necesidad de intervenciones ortopédicas reparadoras. Las placas de crecimiento se consideran menos resistentes que las estructuras circundantes, como huesos y ligamentos, hace que la región sea más susceptible a lesiones. En caso de fractura, la lesión debe ser bien evaluada, buscando el mejor método de reparación, con el menor daño iatrogénico causado por el cirujano, pero con una estabilización ósea satisfactoria. Presentamos el caso 
de un canino joven, mestizo, atendido en el Hospital Universitario Veterinario de la Universidad Federal de Santa María, que presentaba una fractura Salter-Harris tipo I en la porción proximal del húmero derecho, tratado con clavijas intramedulares y banda tensora. El método, aunque sencillo, presenta buena estabilidad del foco de la fractura y retorno del soporte de la extremidad sin comprometer los tejidos blandos.

Palabras clave: Perro, cirugía, línea de crecimiento, osteosíntesis

\section{Introdução}

As fraturas ósseas são causas comuns de atendimentos na clínica cirúrgica veterinária. Consistem no rompimento completo ou incompleto da continuidade de um osso ou cartilagem. As principais causas de fraturas em animais de companhia decorrem de forma direta por traumas aplicados ao tecido ósseo por veículos motorizados, quedas, brigas ou acidentes com armas de fogo (Brinker et al., 1986; Freitas et al., 2013; Slatter, 2007).

Quando fisárias, envolvem a linha de crescimento, onde é menor a resistência em relação aos ossos e ligamentos adjacentes. Esse tipo de fratura apresenta classificação única e de acordo com o esquema de Salter-Harris a partir de sua localização na linha de separação (Schulz et al., 2019; Slatter, 2007). Conforme Freitas et al. (2013), após serem reduzidas, as fraturas podem ser estabilizadas utilizando-se de uma série de técnicas, como talas, pinos intramedulares, fio de aço ortopédico, fixador externo, placa de compressão ou associação destas. Fossum (2014) e Schulz et al. (2019) relatam que na rotina médica veterinária, fraturas em pequenos animais são frequentes, porém fraturas de epífises proximais do úmero são incomuns.

Em consulta prévia ao setor de arquivamento do Hospital Veterinário Universitário da Universidade Federal de Santa Maria (HVU-UFSM), a casuística de fraturas proximais do úmero é rara. Não foi feito um estudo retrospectivo para cálculos estatísticos sobre o assunto, porém não foram encontrados casos dessa lesão nos 27 meses que antecederam esse paciente, o que demonstra a baixa frequência dos casos nesse hospital. Por se tratar de um tipo de fratura não corriqueiro e devido à escassez de dados na literatura acerca do assunto, entendemos relevante o relato do caso, o qual apresentou bons resultados de recuperação após tratamento cirúrgico.

\section{Relato do caso}

Foi atendido no HVU-UFSM, uma cadela, sem raça definida, com um ano e quatro meses de idade e pesando $13,4 \mathrm{~kg}$. A cadela apresentava claudicação do membro torácico direito. Havia histórico de atropelamento por veículo na noite anterior ao atendimento e desde então apresentou dificuldade de apoio do membro torácico ao solo, não demostrando ferimentos externos. Apresentava-se inapetente e com diminuição de ingestão hídrica.

Ao exame clínico observou-se parâmetros dentro da normalidade para a espécie, mas ao exame físico, constatou-se região da escápula direita edemaciada, suspeitando-se de fratura local. A suspeita foi confirmada por meio de exame radiográfico sendo obtidas imagens laterais e ventrodorsais obliquada do membro torácico direito (Figura 1), onde foi excluído diagnóstico diferencial de luxação escapuloumeral e definido como fratura proximal de úmero do membro torácico direito, classificada como de Salter-Harris tipo I, com deslocamento caudal do fragmento distal.

A paciente permaneceu internada recebendo analgesia a base de Cloridrato de Tramadol e Dipirona Sódica, nas doses de $4 \mathrm{mg} / \mathrm{kg}$ e $25 \mathrm{mg} / \mathrm{kg}$ respectivamente, três vezes ao dia (t.i.d.) e anti-inflamatório a base de Carprofeno, $2 \mathrm{mg} / \mathrm{kg}$, duas vezes a dia (b.i.d.). Com os resultados dos exames laboratoriais indicando parâmetros hematológicos e bioquímicos inalterados, encaminhou-se a paciente ao bloco cirúrgico, sendo o procedimento realizado dois dias após a internação, respeitando jejum hídrico de seis horas e alimentar de oito horas prévios à cirurgia.

Após medicação pré-anestésica composta por Acepromazina $0,2 \%(0,03 \mathrm{mg} / \mathrm{kg})$ e Metadona $10 \mathrm{mg}$ $(0,3 \mathrm{mg} / \mathrm{kg})$, ambos por via intramuscular, o animal foi submetido à indução anestésica com Propofol $10 \mathrm{mg}(4 \mathrm{mg} / \mathrm{kg})$ via intravenosa. Logo após procedeu-se a intubação orotraqueal, sendo a sonda conectada ao sistema para manutenção anestésica. O agente anestésico utilizado foi Isoflurano, diluído 
em $100 \%$ de oxigênio durante todo procedimento. Foi realizado bloqueio do plexo nervoso braquial, utilizando Lidocaína com vasoconstritor $2 \%(7 \mathrm{mg} / \mathrm{kg})$.
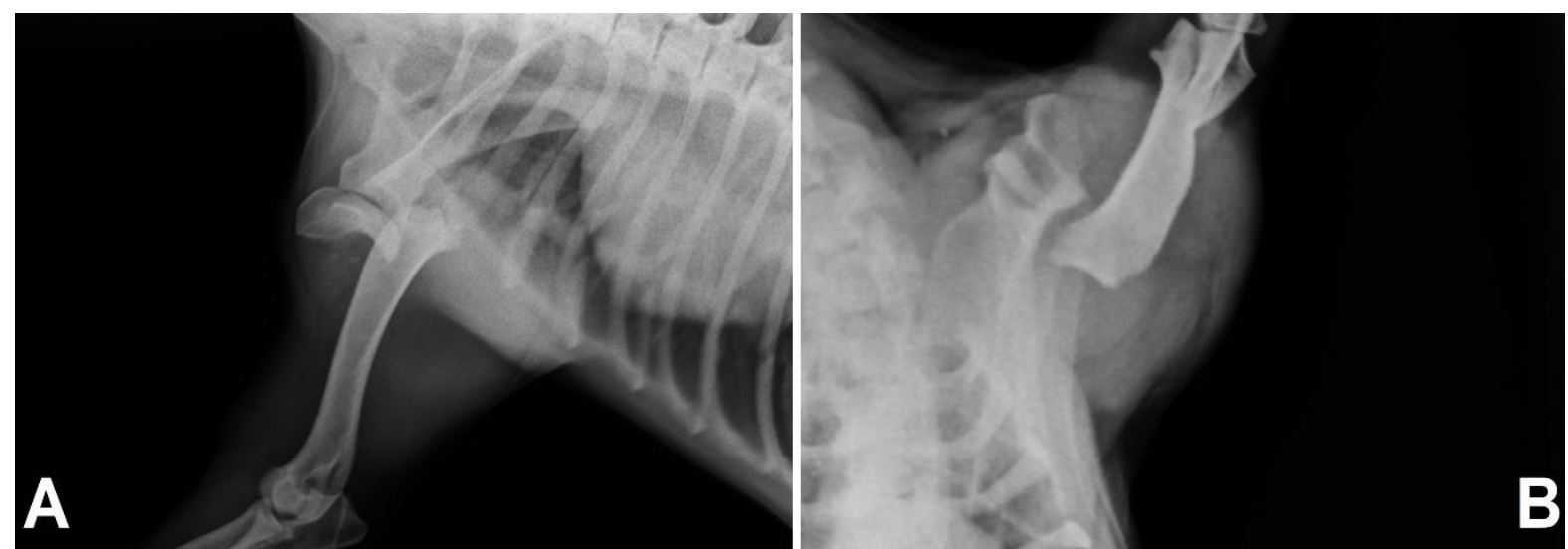

Figura 1. (A) Paciente no $1^{\circ}$ dia de internação. Observar fratura da epífise proximal do úmero, imagem ventro-dorsal obliquada. (B) Observar deslocamento caudal da porção distal do úmero, imagem lateral da articulação escapuloumeral direita.

Com o animal preparado para cirurgia asséptica, foi realizada incisão de pele e subcutâneo sobre a região crânio-lateral da articulação do ombro. Após os músculos braquiocefálico e porção escapular do deltoide foram divulsionados com tesoura de Metzenbaun, sendo exposto o segmento ósseo fraturado. Foi perfurado um orifício no fragmento proximal, em sentido latero-medial, proximal-distal, atravessando a linha de fratura pelo canal medular. Com auxílio da pinça de redução óssea, foi aplicada tração no membro em sentido distal, para que, em movimento único, permitisse o alinhamento e aposição dos fragmentos ósseos.

Os dois pinos inseridos foram fios de Kirschner $\mathrm{n}^{\circ} 2,5 \mathrm{~mm}$, entrando no tubérculo maior do úmero transversalmente à linha de fratura, com auxílio de introdutor manual tipo Jacob. Um fio de aço $\mathrm{n}^{\circ} 2$ foi introduzido no orifício previamente perfurado distal à linha de fratura e laçado em torno do pino proximal no padrão de "oito" formando um dispositivo de banda de tensão (Figura 2).

A musculatura foi reposicionada e o tecido subcutâneo reduzido com fio de ácido poliglicólico $\mathrm{n}^{\circ}$ 2-0 no padrão de sutura contínua em "zigue-zague" e pele aproximada no padrão de sutura colchoeiro horizontal, utilizando fio de náilon $\mathrm{n}^{\mathrm{o}} 3$ 3-0. Logo após o procedimento foi realizado curativo no local e instituído fármacos auxiliares para o tratamento pós-cirúrgico. Repetiu-se o protocolo utilizado nos dias de internação por mais três dias consecutivos. Em avaliações por imagem, o animal apresentou deambulação satisfatória no pós-operatório imediato e claudicação leve em duas semanas do tratamento cirúrgico.
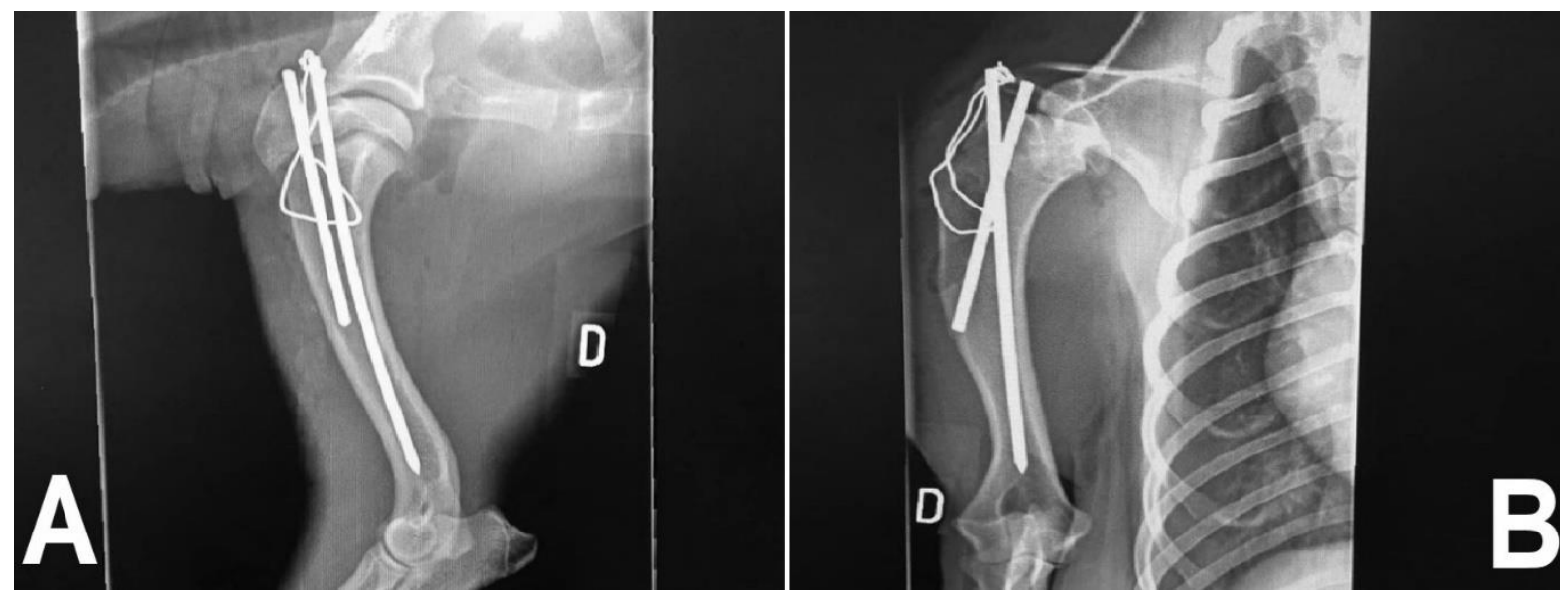

Figura 2. (A) Pós cirúrgico imediato, observar redução da fratura e dispositivo de banda de tensão, imagem lateral da articulação escapuloumeral direita. (B) Pós cirúrgico imediato, imagem dorso-ventral.da articulação escapuloumeral direita. 


\section{Discussão}

No presente caso, o diagnóstico de fratura epifisária da porção proximal do úmero direito foi confirmado através do exame radiográfico, sendo classificada como tipo I pela classificação ortopédica de Salter-Harris, onde a lesão afeta apenas a região fisária (normalmente em decorrência de forças de avulsão), sem envolvimento da metáfise ou núcleo de ossificação epifisário (Salter \& Harris, 1963).

Em cães de porte médio os discos de crescimentos se fecham aproximadamente com um ano de idade, já em animais de raças maiores os discos podem permanecer abertos até 18-20 meses (Von Pfeil, 2009). A linha de crescimento é responsável pelo alongamento do osso, ou seja, permite o crescimento do osso em comprimento (Fré et al., 2016; Junqueira \& Carneiro, 2013). Segundo Von Pfeil \& DeCamp (2009), a linha de crescimento é dividida em três zonas, de repouso, proliferação e hipertrófica. A zona de repouso contém pequenas células de cartilagem disseminadas; zona de proliferação é onde ocorre a formação de centros de replicação celular intersticial da cartilagem; na zona hipertrófica os condrócitos amadurecem e se tornam volumosos devido ao acúmulo de lipídio e glicogênio, além disso, sintetizam fosfatase alcalina o que gera calcificação dessa cartilagem (Fré et al., 2016; Junqueira \& Carneiro, 2013). Johnson et al. (1994) descrevem que as fraturas da fise tendem a ocorrer na zona hipertrófica devido à alta proporção de células.

No caso em questão, o diagnóstico de fratura Salter Harris tipo I umeral foi classificada com base nos dados de literatura. Cabe ressaltar, que, em pequenos animais, esse tipo de fratura tem sido pouco descrito. Tomlinson (2007) cita que fraturas de tubérculo maior, fraturas de separações da epífise proximal (Salter-Harris tipos I e II), fraturas do colo e fraturas metafisárias proximais não são comuns, representando apenas 4,6\% das fraturas umerais em um estudo envolvendo 130 casos. Em consulta ao setor de arquivamento do HVU-UFSM é notável a excepcionalidade desse tipo de caso, sendo que nenhum paciente foi diagnosticado com o mesmo tipo de fratura em um período anterior de 27 meses, o que torna relevante o relato de caso.

Nos casos de fraturas epifisárias proximais do úmero a literatura indica tratamento cirúrgico em detrimento ao conservador (Fossum, 2014). Conforme Schulz et al. (2019), as fraturas fisárias curam rapidamente e, para resguardar o potencial de crescimento ósseo, esse período deve ser levado em consideração na escolha do tipo de tratamento principalmente procurando não interferir no crescimento ósseo, logo deve-se evitar a utilização de método de fixação que o impeça, como placas ósseas ou fixadores externos (Brinker et al., 1986). Sendo necessária a utilização desses métodos, requer-se um segundo procedimento cirúrgico para remoção do implante após o processo de consolidação óssea (Fré et al., 2016). Alguns autores relatam que a redução aberta e fixação interna são indicadas apenas para fraturas que estejam muito deslocadas. Nas demais, o uso de implantes que promovam estabilização, mas não fixação rígida já é suficiente devido à rápida cicatrização (Fré et al., 2016). Assim sendo, os pinos de Steinmann ou fios de Kirschner lisos de pequeno diâmetro, variando de 1 a 2 mm, são os mais adequados na maioria dos casos (Brinker et al., 1986).

Cabe ressaltar que o método ideal de fixação das fraturas da fise do úmero proximal não está estabelecido. Atualmente, há uma falta de conhecimento comparativo sobre a eficácia biomecânica dos métodos de fixação interna para fraturas da fise do úmero proximal (Ma et al., 2017). Os mesmos autores ainda relatam que vários métodos de fixação são descritos, contudo o grau de estabilidade em relação a fixação interna que permitirá o crescimento ósseo em fraturas de placa de crescimento proximal do úmero em cães é desconhecido.

No paciente atendido, optou-se pelo tratamento clínico prévio com uso de analgesia e antiinflamatórios até o momento da realização da cirurgia. Conforme Fossum (2014), bandagens ou talas para fraturas umerais não são recomendadas antes da cirurgia, visto que as configurações-padrão de talas não atingem distância suficientemente proximal para estabilização do osso. O confinamento do animal e a analgesia são indicados.

A técnica cirúrgica de redução de fratura utilizada no paciente baseou-se na aplicação de dispositivo de banda de tensão, sendo relatada por diversos autores (Bojrab, 2005; Niebauer, 1993; Tomlinson, 2007). Schulz et al. (2019) descrevem que no princípio mecânico de um dispositivo de banda de tensão, a fixação do fio exerce força que atua contra a força da contração muscular e comprime a superfície da fratura. O prognóstico da consolidação da fratura e funcionamento do membro é excelente para lesões do úmero proximal, tendo como cuidado pós-operatório inicialmente analgesia e atividade restringida 
até que a fratura esteja consolidada. Um tratamento alternativo para osteossínteses proximais de úmero, principalmente em cães ativos, é descrito por Tomlinson (2007), o qual indica a possibilidade de utilização de parafuso de compressão ou fio Kirschner direcionado caudal e proximal ao interior da cabeça do úmero para proporcionar maior estabilidade a linha de fratura.

A maioria das fraturas fisárias causa lesão das células em crescimento, podendo indicar prognóstico reservado conforme o padrão da lesão, pois quando a função das placas de crescimento é severamente prejudicada, a deformidade anatômica pode se desenvolver. Assim, quanto mais jovem for o animal, maiores as chances de desenvolver distúrbio de crescimento, parada do crescimento ósseo, encurtamento do membro ou defeitos de angulação (Fré et al., 2016; Schulz et al., 2019; Von Pfeil \& DeCamp, 2009).

$\mathrm{O}$ paciente atendido não desenvolveu alterações anatômicas. Acredita-se que este fato se deve pela rápida intervenção e pelo método de tratamento adequado com correta abordagem cirúrgica ao cão enfermo, permitindo a seleção da melhor forma de tratamento, o que garantiu ao paciente o retorno da utilização do membro de maneira precoce e sem alterações.

\section{Conclusão}

Embora sejam escassos os dados acerca desse tipo de fratura, o que torna por si só singular este relato, ressalta-se a importância do diagnóstico correto e do planejamento cirúrgico. Recomenda-se a utilização do duplo pino de Steinmann intramedular associados à banda de tensão, como método de osteossíntese eficaz ao tipo de fratura relatado.

\section{Referências bibliográficas}

Bojrab, M. J. (2005). Técnicas atuais em cirurgia de pequenos animais. Editora Roca.

Brinker, W. O., Piermattei, D. L., \& Flo, G. L. (1986). Manual de ortepedia e tratamento das fraturas dos pequenos animais. Manole São Paulo.

Fossum, T. W. (2014). Cirurgia de pequenos animais (4th ed., Vol. 1). Elsevier Brasil.

Fré, J. C., Marques, S. M. T., \& Alievi, M. M. (2016). Fratura em linha de crescimento de cães e gatos: Revisão. PUBVET, 10, 795-872. https://doi.org/10.22256/pubvet.v10n11.826-834.

Freitas, S. H., Dória, R. G. S., Minto, B. W., Nardi, A. B., Melo, M. M., Camargo, L. M., Santos, M. D., Shimano, A. C., \& Ambrósio, C. E. (2013). Haste intramedular modificada no tratamento de fratura diafisária de fêmur em cão-relato de caso. Brazilian Journal of Veterinary Medicine, 35(4), 323-328.

Johnson, J. M., Johnson, A. L., \& Eurell, J. A. (1994). Histological appearance of naturally occurring canine physeal fractures. Veterinary Surgery, 23(2), 81-86. https://doi.org/10.1111/j.1532-950x.1994.tb00450.x.

Junqueira, L. C., \& Carneiro, J. C. (2013). Histologia Básica (12 ed.). Guanabara Koogan.

Ma, J., Wang, T., Lovric, V., Johnson, K. A., \& Walsh, W. R. (2017). A biomechanical comparison of Kirschnerwire fixation on fracture stability in Salter-Harris type I fractures of the proximal humeral physis in a porcine cadaveric model. BMC Veterinary Research, 13(1), 1-10. https://doi.org/10.1186/s12917-017-1225-y.

Niebauer, G. (1993). Técnicas atuais em cirurgia de pequenos animais. In M. J. Bojrab (Ed.), Current Techniques in Small Animal Surgery. Lea and Febiger.

Salter, R. B., \& Harris, W. R. (1963). Injuries involving the epiphyseal plate. Journal of Bone and Joint Surgery, 45(3), 587-622.

Schulz, K. S., Hayashi, K., \& Fossum, T. W. (2019). Principles of orthopedic surgery and regenerative medicine. In T. W. Fossum (Ed.), Small animal surgery (pp. 957-976). Elselvier Saunders.

Slatter, D. H. (2007). Manual de cirurgia de pequenos animais (Vol. 2). Manole São Paulo.

Tomlinson, J. L. (2007). Fraturas de úmero. In D. Slatter (Ed.), Manual de cirurgia de pequenos animais (pp. 1905-1919). Manole: São Paulo, Brasil.

Von Pfeil, D. J., \& DeCamp, C. E. (2009). The epiphyseal plate: physiology, anatomy, and trauma. Compendium Continuig Education for Veterinarians, 31(8), E1-11.

Von Pfeil, D. J. F. (2009). Orthopedic problems in the immature dog. VeterinarySpecialistsof Alaska, 1(1), 1-10.

Histórico do artigo:

Recebido: 14 de abril de 2021

Aprovado: 9 de junho de 2021
Licenciamento: Este artigo é publicado na modalidade Acesso Aberto sob a licença Creative Commons Atribuição 4.0 (CC-BY 4.0), a qual permite uso irrestrito, distribuição, reprodução em qualquer meio, desde que o autor e a fonte sejam devidamente creditados. 